\title{
Questão social, trabalho e crise em tempos de pandemia
}

Social question, work and crisis in times of pandemic

Maria Carmelita Yazbek ${ }^{a}$

(D) https://orcid.org/0000-0002-4785-472X

Raquel Raichelis ${ }^{a}$

(D) https://orcid.org/0000-0003-3275-3755

Raquel Sant'Ana ${ }^{b}$

(D) https://orcid.org/0000-0002-2270-5541

screvemos este editorial não vislumbrando no horizonte uma perspectiva de esperança, e até mesmo de um futuro próximo, nos tempos sombrios e desumanos que vivemos na atualidade, agravados pela pandemia da COVID-19, quer em termos globais, quer em nosso país. A situação de calamidade pública na qual estamos imersos(as) torna mais visível e aguda a crise e expõe a falácia das contrarreformas neoliberais em nosso país, em favor dos interesses do grande capital e em detrimento das necessidades e direitos das classes trabalhadoras.

A expansão da(s) direita(s) no cenário nacional e internacional, o crescimento do conservadorismo de traços fascistas e a intensa precarização das condições de trabalho e de vida são expressões concretas da atual fase de acumulação do capitalismo internacional, que não podem ser creditadas à pandemia causada pelo novo coronavírus.

No Brasil, a cada dia, em múltiplas iniciativas, o (des)governo federal vem assumindo o projeto ultraliberal conservador e obscurantista, de estímulo ao ódio de classe e aos grupos sociais historicamente excluídos 
de acessos a bens, serviços públicos e direitos, como o povo negro, em especial as mulheres pretas e pobres, os LGBTI+, os(as) jovens periféricos(as) e as classes trabalhadoras destituídas e subalternizadas. A retórica da necessidade de aprovação, pelo Congresso Nacional, das contrarreformas como remédio para a calamidade pública que nos assola não se sustenta, pois, nas situações de crise profunda como a que estamos vivendo, as desigualdades sociais se tornam mais visíveis, atingindo diferencialmente burgueses e trabalhadores, ricos e pobres, centrais e periféricos.

A centralidade do capital financeiro e seu domínio sobre o capital produtivo traz consequências graves para a "classe que vive do trabalho" (Antunes, 2013), com a manutenção de taxas elevadas de desemprego, insegurança e instabilidade nos empregos, crescimento do trabalho informal e precário, redução de salários, precarização das relações de trabalho, incluindo terceirizações e contratos por prazos determinados, assédios, sofrimentos e adoecimentos, entre outros aspectos. Cenário que as contrarreformas neoliberais, principalmente a EC 95, só fizeram agravar, fragilizando o já precário funcionamento do SUS, do SUAS, da Previdência Social, ou seja, exatamente as políticas de Seguridade Social que neste momento estão sendo demandadas para ações emergenciais e preventivas sem prover, contudo, a seus milhares de trabalhadores e trabalhadoras, entre os quais assistentes sociais, condições materiais, técnicas, de segurança e proteção social da vida, indispensáveis para a realização do trabalho social na linha de frente do atendimento à população nos territórios das cidades.

Como sabemos, a desigualdade e a concentração de renda, que se intensificam nas atuais formas de acumulação capitalista, resultam de mudanças na esfera da produção, associadas à nova hegemonia liberal-financeira, e trazem como consequência o agravamento da "questão social" e suas expressões na vida da classe trabalhadora. No Brasil, estamos diante de uma sociedade "desigualitária sem remissão", como lembra Francisco de Oliveira (2003, p. 146), que no tempo presente radicaliza a "questão social" e amplia estratégias de subalternização, reconfigurando formas e significados das políticas públicas e dos sistemas de proteção social. 
Como nos lembra Iamamoto (2018, p. 72), a questão social brasileira, nos contraditórios tempos presentes, assume configurações e expressões que

condensam múltiplas desigualdades mediadas por disparidades nas relações de gênero, características étnico-raciais, mobilidades espaciais, formações regionais e disputas ambientais, colocando em causa amplos segmentos da sociedade civil no acesso aos bens da civilização. Dispondo de uma dimensão estrutural — enraizada na produção social contraposta à apropriação privada do trabalho - , a questão social atinge visceralmente a vida dos sujeitos numa luta aberta e surda pela cidadania, no embate pelo respeito aos direitos civis, sociais e políticos e aos direitos humanos.

Nesta edição da revista Serviço Social \& Sociedade será possível aos(às) leitores(as) aprofundar a reflexão sobre a "questão social" em múltiplas dimensões, um debate necessário que deve ser permanentemente reatualizado. Dimensão transversal presente na quase totalidade dos artigos, vários trazem contribuições relevantes, entre os quais vale menção à original (e polêmica) reflexão sobre a abordagem da questão social na [ex] União Soviética. Baseando-se nas elaborações de Mészáros (2009), e ilustrando com os estudos de Mandel (2017) sobre as famílias operárias, o autor argumenta que a União Soviética pós-revolução socialista não alterou o comando do capital sobre o trabalho, que permaneceu alienado e desumanizado, porém sob o controle da burocracia estatal. 0 texto destaca que apreender criticamente o sistema do capital implica ir além da análise do capitalismo, à medida que a lógica da exploração do trabalho permanece, sobrepondo os interesses do capital sobre o trabalho e, portanto, reproduzindo o antagonismo de classe e suas resultantes como a miséria e o pauperismo da classe trabalhadora.

Esse é um debate importante para o Serviço Social brasileiro, e nos alerta para a análise das relações sociais a partir das relações materiais desenvolvidas nas diferentes sociabilidades e na concretude do que definimos como classe trabalhadora, ou seja, homens e mulheres com diferentes sexos e sexualidades, diversas origens étnico-raciais e 
regionais. Diferenças que na sociedade do capital foram apropriadas de maneira a alicerçar os pilares da exploração e opressão de segmentos sociais majoritários ao longo da história.

Neste número, três artigos trazem ao debate processos que evidenciam a presença da violência de classe na sociedade brasileira, seja na relação entre os sexos que vem marcando a nossa história, colocando em evidência o patriarcado e as relações machistas, racistas e sexistas que essa sociedade escravocrata e colonial construiu; seja na perspectiva de ódio de classe e extermínio de travestis e transexuais no país. As análises e os dados expostos nos textos confirmam a assertiva de que a violência constitui elemento estruturante e fundamental de enquadramento no ordenamento social de gênero, seja na constituição das relações íntimas que configuram a violência doméstica contra a mulher - que se agrava dramaticamente na situação de confinamento social determinada pela pandemia - seja na construção histórica de uma estrutura racial e sexista que alija pessoas negras, mulheres, LGBTI+. Trata-se de uma estrutura construída por práticas sociais genocidas que marcaram a história brasileira e que expressam, conforme um dos artigos, um "projeto de Estado neoliberal que promove a invisibilidade e o extermínio dessas pessoas".

Tendo esse quadro mais geral presente, há um conjunto de artigos que se debruçam sobre o trabalho profissional e os(as) trabalhadores(as) assistentes sociais, que expressam as reconfigurações do trabalho e os impactos nas atribuições, competências e autonomia profissionais, processos que de modo geral reproduzem as condições de precariedade e superexploração da força de trabalho a que são submetidas as classes trabalhadoras em seu conjunto (cf. Raichelis, 2018 e 2020).

$O$ artigo sobre sofrimento no trabalho na Previdência Social mediado pelas tecnologias digitais é parte de uma pesquisa mais ampla sobre processo de trabalho e a saúde de assistentes sociais que atuam nos Serviços de Seguridade Social no Brasil. No caso da pesquisa com assistentes sociais da Previdência Social, objeto da análise, além do impacto das TICs na redução do trabalho vivo, com enxugamento drástico do número de 
assistentes sociais, a reflexão apontou o sofrimento dos(as) trabalhadores(as) diante da iminência de extinção do Serviço Social, dinâmica que acompanha a categoria profissional desde meados da década de 1990. Também o artigo sobre trabalho docente em universidades públicas, no caso do Rio Grande do Norte, fruto de pesquisa de pós-doutorado, registra as consequências devastadoras da incorporação das lógicas privatista e mercantil nas IES públicas e seus rebatimentos no trabalho docente, com rebaixamento salarial e desqualificação do trabalho de pesquisa e de produção intelectual. Processo potencializado pelo uso intensivo das tecnologias de informação e comunicação, que intensificam a e precarizam ainda mais as condições de trabalho, provocam a fusão entre tempo de trabalho e tempo de não trabalho, desencadeando desgastes físicos e mentais, sofrimentos e adoecimentos. Ainda tratando dos desafios do trabalho profissional, esta edição da revista traz relevante contribuição para problematizar a escuta especializada de crianças e adolescentes testemunhas ou vítimas de violência, tema que vem mobilizando todos(as) que trabalham nas instituições que integram o SGD (Sistema de Garantia de Direitos). $O$ artigo aborda as ambiguidades de uma legislação supostamente protetora de direitos, mas que num contexto de criminalização da pobreza e precárias condições de trabalho, vem levando à priorização da produção de provas antecipadas, colidindo com a regulamentação profissional e os valores que orientam o projeto ético-político do Serviço Social.

Outro conjunto de textos aproxima leitores(as) do Serviço Social no cenário mundial, em sua diversidade e num contexto de mudanças globais, que vêm alterando as requisições e os desafios colocados à profissão. Segundo Yazbek e Iamamoto (2019, p. 11), "constata-se uma lacuna na produção acadêmica brasileira quanto ao reconhecimento do Serviço Social no circuito mundial nas últimas décadas”. Daí a relevância de trazer ao conhecimento do público mais amplo da Serviço Social \& Sociedade as tendências e desafios do Serviço Social em outros países, considerando a "unidade na diversidade" provocada pelas determinações do processo de mundialização do capital e seus rebatimentos nas diferentes sociedades nacionais. 
Um dos artigos analisa a gênese do Serviço Social e o debate sobre a ética realizados no Brasil e na Itália, evidenciando as distintas bases doutrinárias e matrizes teórico-metodológicas que presidem os respectivos projetos profissionais: de um lado, o Serviço Social brasileiro e os fundamentos marxianos e marxistas do Projeto Ético-Político, que alimenta a direção estratégica do conhecimento e do trabalho profissional; e, de outro, o caminho seguido pela profissão na Itália, pautado em uma ética personalista, cujos fundamentos ecléticos envolvem referências ao personalismo e ao neotomismo, de matriz positivista e fenomenológica. Nesse interessante painel, ainda que parcial, sobre o Serviço Social no circuito internacional, o artigo sobre a profissão na Inglaterra, produto de um estágio de pesquisa de doutorado, contribui para uma aproximação ao debate contemporâneo do Serviço Social inglês por meio do pensamento de alguns dos autores mais expressivos representante do denominado "radical social work", corrente crítica ao Serviço Social tradicional, de inspiração marxista, pautada em valores humanistas de defesa da justiça social e compromisso com as lutas feministas e antirracistas.

O balanço do conjunto dos artigos que compõem este número da revista Serviço Social \& Sociedade revela um rico painel de questões que pretendem contribuir para a leitura crítica das diferentes dimensões que configuram a "questão social" na cena contemporânea, e instigar assistentes sociais e demais profissionais na árdua tarefa de repensar táticas e estratégias de trabalho em tempos de devastação do trabalho e de pandemia.

Se o compromisso profissional é com a superação da exploração e das opressões, a análise que recupera e adensa os seus determinantes societários é um instrumento fundamental para buscar alternativas que coloquem o compromisso com a vida e com os direitos dos indivíduos sociais em primeiro lugar. Em tempos de desmonte das frágeis e insuficientes políticas públicas, esse é um quadro que interpela profundamente aqueles(as) que buscam uma outra sociabilidade para além do capital. 


\section{Referências}

ANTUNES, Ricardo (org.). Riqueza e miséria do trabalho no Brasil II. São Paulo: Boitempo, 2013.

IAMAMOTO, Marilda V. Serviço Social, "questão social" e trabalho em tempo de capital fetiche. In: RAICHELIS, R. et al. (orgs.) A nova morfologia do trabalho no Serviço Social. São Paulo: Cortez, 2018.

MANDEL, David. Rabotyagi. Uma visão dos de baixo, após a Perestroika. In: PANIAGO, Maria Cristina Soares. Mészáros e a crítica à experiência soviética. São Paulo: Instituto Lukács, 2017.

MÉSZÁROS, István. Para além do capital: rumo a uma teoria da transição. São Paulo: Boitempo, 2009.

OLIVEIRA, Francisco de. Crítica à razão dualista/O ornitorrinco. São Paulo: Boitempo, 2003.

RAICHELIS, Raquel. Serviço Socal: trabalho e profissão na trama do capitalismo contemporâneo. In: RAICHELIS, Raquel et al. (orgs.). A nova morfologia do trabalho no Serviço Social. São Paulo: Cortez, 2018.

RAICHELIS, Raquel. Atribuições e competências profissionais revisitadas: a nova morfologia do trabalho no Serviço Social. In: CFESS (org.). Atribuições privativas do/a assistente social em questão - vol 2. Brasília, CFESS, 2020. Disponível em: http://www.cfess.org. br/arquivos/CFESS202-AtribuicoesPrivativas-Vol2-Site.pdf. Acesso em: 10 abr. 2020.

YAZBEK, Maria Carmelita; IAMAMOTO, Marilda Villela. Serviço Social na História América Latina, África e Europa. São Paulo: Cortez, 2019.

\section{Sobre as autoras}

Maria Carmelita YazbeK - Assistente social. Doutora em Serviço Social. Professora e pesquisadora do Programa de Estudos Pós-Graduados em Serviço Social da PUC-SP.

E-mail: mcyaz@uol.com.br

Raquel Raichelis Degenszajn - Assistente social. Doutora em Serviço Social. Professora do Programa de Estudos Pós-Graduados em Serviço Social da PUC-SP. E-mail: raichelis@uol.com.br

Raquel Santos Sant'Ana - Doutora em Serviço Social.

E-mail: raquelssfranca@yahoo.com.br 
